\title{
Early single photon emission computed tomography in Sturge-Weber syndrome
}

\author{
F Pinton, C Chiron, O Enjolras, J Motte, A Syrota, O Dulac
}

Hospital Frédéric Joliot, Departmentt of Medical Research, Atomic Energy Committee, Orsay, France

F Pinton

C Chiron

A Syrota

Department of Neuropediatrics, Hospital

Saint-Vincent-de-Paul, and INSERM U29, Paris, France

F Pinton

C Chiron

O Dulac

Department of Dermatology, Hospital Cochin, Tarnier, Paris, France

O Enjolras

Department of Neuropediatrics, American Memorial Hospital, Reims, France

J Motte

Correspondence to: Dr C Chiron, Department of Neuropediatrics, Hospital Saint-Vincent-de-Paul, 82 Avenue Denfert-Rochereau, 75674 Paris Cedex 14,

France.

Received 5 December 1996 and in final revised form 29 April 1997

Accepted 6 May 1997

\begin{abstract}
Objectives-Functional cerebral imaging PET and SPECT have shown hypometabolism and hypoperfusion in the area of vascular malformation in children with epilepsy due to Sturge-Weber syndrome. However, data are scarce in infants and do not exist in patients with Sturge-Weber disease without epilepsy. The pattern of perfusion during the first two years of life was studied including patients before the onset of seizures.
\end{abstract}

Methods-Twenty two infants with later confirmed Sturge-Weber disease underwent SPECT examination using TOMOMATIC 564 (Medimatic) and xenon-133 at ages ranging from 8 days to 25 months. Twelve had never had seizures before SPECT and seven underwent $a$ second SPECT a mean seven months later. Cerebral blood flow (CBF) was measured in the whole hemisphere and in the part of the cortex involved in the vascular malformation on both sides as well as a "pathological to normal" index for the hemisphere and vascular malformation. These values were compared with normal age paired values.

Results-Compared with controls, CBF and the indices in the hemisphere and vascular malformation were significantly decreased in patients who already had had seizures before SPECT, whereas they were significantly increased in $75 \%$ of the patients who had never had any seizures. On second SPECT, the indices were decreased in all patients, including the four who still remained non-epileptic.

Conclusions-SPECT therefore detects CBF asymmetry in infants with SturgeWeber disease, which tends to shift with age. The cortex involved in the vascular malformation is hyperperfused during the first year of life before first seizures. The classic hypoperfusion appears after one year of age, even in non-epileptic patients.

(F Neurol Neurosurg Psychiatry 1997;63:616-621)

Keywords: Sturge-Webe diseaser; SPECT; children

Sturge-Weber angiomatosis is a neurocutaneous syndrome characterised by a congenital port wine stain, ipsilateral pia mater vascular malformation, and ipsilateral vascular abnormalities of the eye (choroidal angioma and glaucoma). ${ }^{1}$ The diagnosis is usually considered at birth in a child with a facial capillary malformation including the trigeminal ophthalmic V1 area. ${ }^{2}$ Epilepsy is a very common feature and often occurs during the first year of life. ${ }^{45}$ Diagnosis of Sturge-Weber disease is confirmed by imaging investigations. Brain CT and MRI are reliable techniques in childhood to demonstrate the intracranial vascular malformation when they show unilateral hypertrophy of the choroid plexus, calcifications, focal atrophy, and hyperdensity or hypersignal after contrast injection. ${ }^{6-9}$ In infants, diagnosis of Sturge-Weber disease may be difficult before seizures and radiological characteristics appear. ${ }^{5-7}$ The current "gold standard" for diagnosis of the disease, which seems to be reliable even in very young infants, is pial enhancement on MRI after gadolinium administration. ${ }^{10-12}$ There is clinical evidence that the occurence of epilepsy worsens the neurological status of patients with SturgeWeber disease. Prolonged seizures may result in definite hemiplegia whereas no motor asymmetry was detectable before the seizures. ${ }^{145}$ Adult patients with rare seizures or without epilepsy can be socially integrated whereas children with intractable epilepsy have severe mental retardation. ${ }^{145}$ However, progressive hemiatrophy may be present in some patients without frequent seizures. ${ }^{513}$ Functional cerebral studies using PET and single photon emission computed tomography (SPECT) have shown abnormalities of metabolism and perfusion in Sturge-Weber disease. ${ }^{14-17}$ All examinations were performed in epileptic children interictally, and showed hypometabolism and hypoperfusion in the area of vascular malformation, which was usually more extended than the associated abnomalities on CT and MRI as it included the cerebral parenchyma under the malformed pia mater. These studies concerned children with a large range of ages, but there were very few patients under two years of age. In the three youngest infants, a paradoxical interictal pattern of hypermetabolism and hyperperfusion has been reported. ${ }^{14} 18$ The purpose of our study was to define whether a characteristic regional cerebral blood flow (rCBF) pattern does exist before any seizures in patients with Sturge-Weber syndrome. Because a progressive process has been suspected from radiological data, we focused on a population of infants younger than 2 years.

Patients and methods

PATIENTS

Twenty two patients entered in the study, 14 boys and eight girls, aged from 8 days to 


\begin{tabular}{|c|c|c|c|c|c|c|c|c|c|c|}
\hline \multirow[b]{2}{*}{$\begin{array}{l}\text { Patient } \\
\text { No }\end{array}$} & \multirow[b]{2}{*}{ Sex } & \multirow[b]{2}{*}{$\begin{array}{l}\text { Cutaneous } \\
\text { angioma }\end{array}$} & \multirow[b]{2}{*}{$\begin{array}{l}\text { Seizures before SPECT } \\
\text { (age at 1st seizure) }\end{array}$} & \multicolumn{6}{|c|}{ Characteristics at the time of SPECT examination } & \multirow[b]{2}{*}{ Follow up } \\
\hline & & & & Age & CT signs & MRI signs & $A E D$ & $\begin{array}{l}\text { Neurological } \\
\text { examination }\end{array}$ & $\begin{array}{l}\text { Mental } \\
\text { development }\end{array}$ & \\
\hline \multirow[t]{2}{*}{1} & M & Left & No & 8 days & None & WMH & None & & Normal & $2 \mathrm{y}$ \\
\hline & & & No & $10 \mathrm{~m}$ & & None & $\mathrm{PB}$ & Normal & Normal & \\
\hline \multirow[t]{2}{*}{2} & M & Left & No & 15 days & $\mathrm{PH}$ & WMH, $\mathrm{PH}^{\star}$ & None & Normal & Normal & $1 \mathrm{y}$ \\
\hline & & & No & $10 \mathrm{~m}$ & & $\mathrm{~A}, \mathrm{PH}$ & $\mathrm{PB}$ & $\mathrm{R}$ hemianopsia & Normal & \\
\hline 3 & $\mathrm{~F}$ & Left & $\begin{array}{l}\text { No }(14 \mathrm{~m}) \\
\text { No }(14 \mathrm{~m})\end{array}$ & $\begin{array}{l}17 \text { days } \\
11 \mathrm{~m}\end{array}$ & None & $\begin{array}{l}\text { WMH } \\
\text { None }\end{array}$ & $\begin{array}{l}\text { None } \\
\text { PB }\end{array}$ & $\begin{array}{l}\text { Normal } \\
\text { Normal }\end{array}$ & $\begin{array}{l}\text { Normal } \\
\text { Normal }\end{array}$ & $1.5 \mathrm{y}$ \\
\hline 4 & $\mathrm{~F}$ & Right & No $(3 \mathrm{~m})$ & $1 \mathrm{~m}$ & & None & $\mathrm{PB}$ & Normal & Normal & $2 \mathrm{y}$ \\
\hline \multirow[t]{2}{*}{5} & M & Left & No $(6 \mathrm{~m})$ & $1 \mathrm{~m}$ & $\mathrm{PH}$ & & $\mathrm{PB}$ & Normal & Mildly delayed & $6 y$ \\
\hline & & & Yes $(6 \mathrm{~m})$ & $10 \mathrm{~m}$ & $\mathrm{PH}, \mathrm{A}, \mathrm{CE}$ & A & PB & Normal & Normal & $6 \mathrm{y}$ \\
\hline 6 & $M$ & Right & No & $1 \mathrm{~m}$ & A & A, PH, WMH & $\mathrm{PB}$ & Normal & Normal & $6 \mathrm{~m}$ \\
\hline \multirow[t]{2}{*}{7} & $M$ & Right & No & $1 \mathrm{~m}$ & $\mathrm{PH}$ & WMH & None & Normal & Normal & $2 \mathrm{y}$ \\
\hline & $M$ & Left & $\begin{array}{l}\text { No } \\
\text { No }\end{array}$ & $\begin{array}{l}6 \mathrm{~m} \\
1.5 \mathrm{~m}\end{array}$ & None & None & $\begin{array}{l}\text { PB } \\
\text { PB }\end{array}$ & $\begin{array}{l}\text { Normal } \\
\text { Normal }\end{array}$ & $\begin{array}{l}\text { Normal } \\
\text { Normal }\end{array}$ & $1 \mathrm{y}$ \\
\hline 9 & $\mathrm{~F}$ & Left & No $(23 \mathrm{~m})$ & $1.5 \mathrm{~m}$ & None & None & $\mathrm{PB}$ & Normal & Normal & $2 y$ \\
\hline \multirow{2}{*}{10} & F & Right & No $(3 \mathrm{~m})$ & $2 \mathrm{~m}$ & $\mathrm{PH}$ & WMH & $\mathrm{PB}$ & Normal & Normal & $2 \mathrm{y}$ \\
\hline & & & Yes $(3 \mathrm{~m})$ & $7 \mathrm{~m}$ & & A & $\mathrm{CBZ}$ & Normal & Normal & \\
\hline \multirow[t]{2}{*}{11} & $M$ & Left & No $(7 \mathrm{~m})$ & $3.5 \mathrm{~m}$ & $\mathrm{PH}$ & & None & Normal & Normal & $5 y$ \\
\hline & & & Yes $(7 \mathrm{~m})$ & $7.5 \mathrm{~m}$ & $\mathrm{PH}$ & & $\mathrm{PB}$ & $\mathrm{R}$ hemiparesis & Normal & $7 y$ \\
\hline 12 & $M$ & Right & No & $12 \mathrm{~m}$ & A & A & $\mathrm{PB}$ & Normal & Normal & $5 y$ \\
\hline 13 & $\mathrm{~F}$ & Bilateral & Yes (7 days) & $2 \mathrm{~m}$ & $\mathrm{~A}, \mathrm{PH}$ & A, WMH & $\mathrm{PB}$ & Hypotonia & Severely delayed & $4 y$ \\
\hline 14 & $\mathrm{~F}$ & $\begin{array}{l}\text { Right } \\
\text { Rint }\end{array}$ & Yes ( 1 day) & $2.5 \mathrm{~m}$ & $\mathrm{~A}, \mathrm{CE}$ & & $\mathrm{PB}$ & Normal & Mildly delayed & $7 \mathrm{y}$ \\
\hline 15 & M & Left & Yes $(3 \mathrm{~m})$ & $3.5 \mathrm{~m}$ & A, CE, PH & & $\mathrm{PB}, \mathrm{CZP}$ & R hemiplegia & Normal & $1.5 \mathrm{y}$ \\
\hline 16 & $\mathrm{~F}$ & Left & Yes $(9 \mathrm{~m})$ & $9 \mathrm{~m}$ & None & & CBZ, CLB & $\mathrm{R}$ hemiparesis & Speech delayed & $7 \mathrm{y}$ \\
\hline 17 & $\mathrm{~F}$ & Left & Yes $(6 \mathrm{~m})$ & $9 \mathrm{~m}$ & None & CE, WMH & VPA & & Normal & $5 y$ \\
\hline 18 & $\mathrm{M}$ & Left & Yes $(4 \mathrm{~m})$ & $11 \mathrm{~m}$ & $\mathrm{CE}, \mathrm{C}$ & & $\mathrm{PB}$ & R hemiplegia & Mildly delayed & $3 \mathrm{y}$ \\
\hline 19 & $M$ & None & Yes (3 weeks) & $13 \mathrm{~m}$ & A, C & & PB & L hemiparesis & Speech delayed & $7 \mathrm{y}$ \\
\hline 20 & $\mathrm{M}$ & Right & Yes $(3 \mathrm{~m})$ & $15 \mathrm{~m}$ & $\mathrm{~A}, \mathrm{CE}$ & $\mathrm{A}, \mathrm{CE}, \mathrm{WMH}$ & CBZ, CZP & L hemiplegia & Severely delayyed & $1.5 \mathrm{y}$ \\
\hline 21 & $M$ & Left & Yes $(13 \mathrm{~m})$ & $17 \mathrm{~m}$ & $\mathrm{OE}$ & & CBZ & Normal & Mildly delayed & $8 \mathrm{y}$ \\
\hline 22 & M & Left & Yes $(11 \mathrm{~m})$ & $24 \mathrm{~m}$ & $\mathrm{~A}, \mathrm{CE}$ & A & CBZ & Normal & Speech delayed & $2 \mathrm{y}$ \\
\hline
\end{tabular}

${ }^{\star}$ Injection of gadolinium performed.

$\mathrm{m}=$ months; $\mathrm{y}=$ years $\mathrm{PH}=$ choroid plexus hypertrophy; $\mathrm{A}=$ atrophy; $\mathrm{CE}=$ contrast enhancement $\mathrm{C}=$ calcifications; $\mathrm{WMH}=$ white matter hypersignal; $\mathrm{AED}=$ antiepileptic drugs; $\mathrm{PB}=$ phenobarbitone; $\mathrm{CBZ}=$ carbamazepine $\mathrm{CLB}=$ clobazam; $\mathrm{CZP}=$ clonazepam.

25 months, with confirmed Sturge-Weber syndrome at follow up based on the presence of at least two features among facial port wine stain, seizures, and CT or MRI abnormalities (table 1). Twelve patients had never had seizures before SPECT imaging. Among the patients without seizures, seven underwent two SPECT examinations. The control population came from a previously published study. ${ }^{19}$ These subjects had transient abnormal symptoms (sleep myoclonia, syncope, benign neonatal convulsions, or facial port wine stain without Sturge-Weber disease) and cerebral imaging was needed to confirm the integrity of the brain; they all had normal neurological examination, EEG, and CT at the time of the investigation. In all patients informed consent was obtained from either the parent or guardian after a full explanation of the investigative procedures. The study of control patients was also approved by the institutional and technical ethics committees for radiation studies.

\section{METHODS}

The SPECT was performed in accordance with the ethical committees of French Public Hospitals and the French Atomic Energy Committee guidelines, and with informed consent of the parents. The $\mathrm{rCBF}$ was measured using a TOMOMATIC 564 (Medimatic), a high sensitive brain dedicated SPECT system and xenon-133, ${ }^{19}$ injected intravenously at doses ranging from 74 to $148 \mathrm{MBq} / \mathrm{kg}$. The radiation dose to the target organ, the lung, was 2.5 to $4.5 \mathrm{mGy}$. Acquisition began as soon as the tracer had been injected and lasted five minutes. To prevent the head from moving during acquisition, the children received 4 $\mathrm{mg} / \mathrm{kg}$ rectal pentobarbitone and either 50 $\mathrm{mg} / \mathrm{kg}$ oral chloral hydrate or $0.5 \mathrm{mg} / \mathrm{kg}$ intramuscular droperidol. The system provided five axial $20 \mathrm{~mm}$ thick slices, parallel to the orbitomeatal line. $\mathrm{rCBF}$ was measured in 18 circular cortical regions of interest (ROIs) per slice to calculate hemispheric $\mathrm{CBF}$ and rCBF in the vascular malformation. Two hemispheric $\mathrm{CBF}$ values were obtained at each SPECT study by averaging the nine ROIs of each side on the three central slices. To assess rCBF in the vascular malformation, we localised the hypoperfused area found on SPECT images in a given patient and corresponding to parenchymal abnormalities on CT or MRI. rCBF was calculated in four cortical regions (frontal cortex, sensorimotor cortex, polymodal parietotemporal associative cortex, and unimodal parietotemporo-occipital associative cortex), by averaging several ROIs on different slices according to a previously reported procedure. ${ }^{19}$ Angioma localisation was expressed in relation to these four regions and $\mathrm{rCBF}$ in the vascular malformation defined by averaging the $\mathrm{CBF}$ values of those affected by the vascular malformation. The corresponding rCBF was also calculated on the normal side. Two types of indices were statistically analysed: absolute CBF values and the index of CBF. The index was defined as follows:

$2 \times \mathrm{CBF}$ on vascular malformation side - $\mathrm{CBF}$ on normal side

$\mathrm{CBF}$ on vascular malformation side $+\mathrm{CBF}$ on normal side.

For each patient, we therefore calculated (table 2) hemispheric CBF on the vascular malformation side and the normal side; 
Table 2 Individual CBF data at first SPECT

\begin{tabular}{|c|c|c|c|c|c|c|c|c|}
\hline Patient No & $\begin{array}{l}\text { Age at } \\
\text { SPECT }\end{array}$ & $\begin{array}{l}\text { Seizures } \\
\text { before } \\
\text { SPECT }\end{array}$ & $\begin{array}{l}\text { Hem } C B F \\
\text { angioma } \\
\text { side }\end{array}$ & $\begin{array}{l}\text { Hem } C B F \\
\text { normal side }\end{array}$ & $\begin{array}{l}r C B F \\
\text { angioma } \\
\text { side }\end{array}$ & $\begin{array}{l}r C B F n l \\
\text { side }\end{array}$ & Hem index & Reg index \\
\hline 1 & 8 days & No & $70(46)$ & $67(46)$ & $87(50)$ & $76(56)$ & $0.04(0)$ & $0.13(-0.11)$ \\
\hline 2 & 15 days & No & $34(46)$ & $32(46)$ & $36(50)$ & $34(50)$ & $0.06(0)$ & $0.06(0)$ \\
\hline 3 & 17 days & No & $58(46)$ & $44(46)$ & $50(42)$ & $41(42)$ & $0.27(0)$ & $0.2 \quad(0)$ \\
\hline 4 & $1 \mathrm{~m}$ & No & $74(46)$ & $66(46)$ & $88(50)$ & $72(51)$ & $0.11(0)$ & $0.2 \quad(-0.02)$ \\
\hline 5 & $1 \mathrm{~m}$ & No & $41(46)$ & $38(46)$ & $43(51)$ & $39(50)$ & $0.08(0)$ & $0.1 \quad(0.02)$ \\
\hline 6 & $1 \mathrm{~m}$ & No & $32(46)$ & $49(46)$ & $30(50)$ & $54(50)$ & $-0.42(0)$ & $-0.57(0)$ \\
\hline 7 & $1 \mathrm{~m}$ & No & $66(46)$ & $64(46)$ & $81(53)$ & $82(52)$ & $0.03(0)$ & $-0.01(0.02)$ \\
\hline 8 & $1.5 \mathrm{~m}$ & No & $59(46)$ & $59(46)$ & $71(50)$ & $70(51)$ & $0 \quad(0)$ & $0.01(-0.02)$ \\
\hline 9 & $1.5 \mathrm{~m}$ & No & $56(46)$ & $64(46)$ & $51(50)$ & $66(50)$ & $-0.13(0)$ & $-0.25(0)$ \\
\hline 10 & $2 \mathrm{~m}$ & No & $45(49)$ & $43(50)$ & $49(50)$ & $43(51)$ & $0.05(-0.02)$ & $0.13(-0.02)$ \\
\hline 11 & $3.5 \mathrm{~m}$ & No & $60(52)$ & $55(51)$ & $50(47)$ & $38(43)$ & $0.09(0.02)$ & $0.27(0.09)$ \\
\hline 12 & $12 \mathrm{~m}$ & No & $64(62)$ & $73(65)$ & $66(63)$ & $75(64)$ & $-0.13(-0.05)$ & $-0.12(-0.02)$ \\
\hline 13 & $2 \mathrm{~m}$ & Yes & $57(50)$ & $58(49)$ & $53(51)$ & $55(50)$ & $-0.02(0.02)$ & $-0.04(0.02)$ \\
\hline 14 & $2.5 \mathrm{~m}$ & Yes & $41(53)$ & $45(53)$ & $42(60)$ & $48(59)$ & $-0.09(0)$ & $-0.13(0.02)$ \\
\hline 15 & $3.5 \mathrm{~m}$ & Yes & $39(54)$ & $46(52)$ & $34(55)$ & $43(53)$ & $-0.16(0.04)$ & $-0.22(0.04)$ \\
\hline 16 & $9 \mathrm{~m}$ & Yes & $50(58)$ & $69(57)$ & $48(59)$ & $71(58)$ & $-0.32(0.02)$ & $-0.39(0.02)$ \\
\hline 17 & $9 \mathrm{~m}$ & Yes & $64(58)$ & $70(57)$ & $65(56)$ & $70(56)$ & $-0.09(0.02)$ & $-0.08(0)$ \\
\hline 18 & $11 \mathrm{~m}$ & Yes & $48(65)$ & $70(62)$ & $47(63)$ & $67(62)$ & $-0.37(0.05)$ & $-0.36(0.02)$ \\
\hline 19 & $13 \mathrm{~m}$ & Yes & $41(65)$ & $71(67)$ & $36(73)$ & $76(69)$ & $-0.54(-0.03)$ & $-0.71(0.06)$ \\
\hline 20 & $15 \mathrm{~m}$ & Yes & $38(68)$ & $62(65)$ & $37(69)$ & $61(64)$ & $-0.48(0.05)$ & $-0.5 \quad(0.08)$ \\
\hline 21 & $17 \mathrm{~m}$ & Yes & $58(66)$ & $68(67)$ & $45(68)$ & $67(71)$ & $-0.16(-0.02)$ & $-0.4 \quad(-0.04)$ \\
\hline 22 & $24 \mathrm{~m}$ & Yes & $50(65)$ & $74(66)$ & $38(67)$ & $68(69)$ & $-0.39(-0.02)$ & $-0.57(-0.03)$ \\
\hline
\end{tabular}

The values in parentheses correspond to the normal values for the same age.

$\mathrm{CBF}=$ cerebral blood flow; Hem $\mathrm{CBF}=$ hemispheric cerebral blood flow; $\mathrm{rCBF}=$ regional cerebral blood flow; Hem = hemispheric; $\mathrm{Reg}=$ regional; $\mathrm{m}=$ months.

$\mathrm{rCBF}$ on the vascular malformation and the corresponding region in the normal side; hemispheric index, in which CBF was hemispheric $\mathrm{CBF}$; and regional index, in which $\mathrm{CBF}$ was regional CBF. These values were compared with the corresponding values calculated in age paired controls, with respect to the left-right side in patients and controls. The parametric two sample $t$ test and the nonparametric Mann-Whitney test were used for statistical analysis.

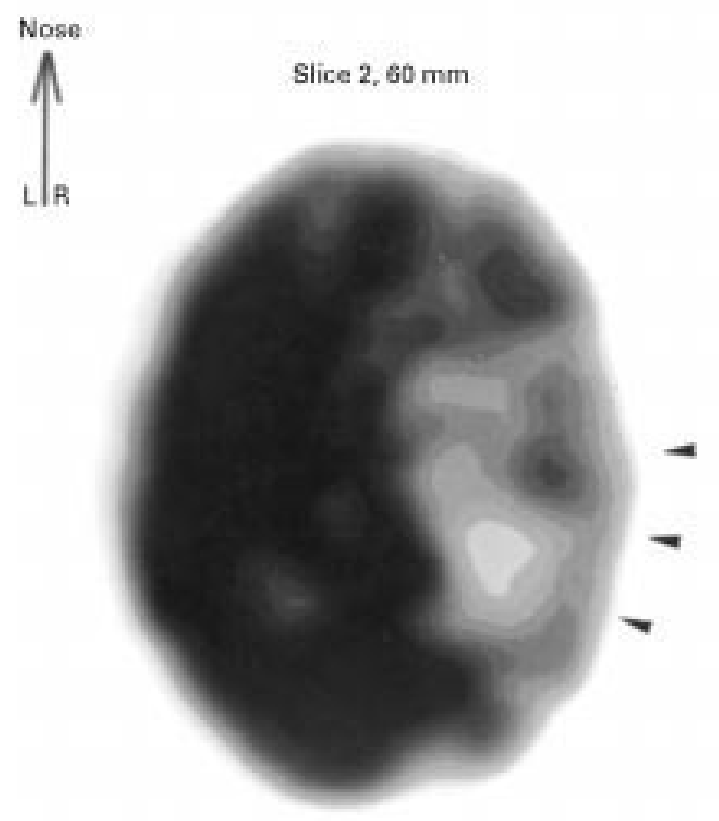

$90-$

$90-$

$70-$

$60-$

$50-$

$40-$

$30-$

$20-$

$10-$

$0-$

Figure 1 Interictal SPECT image obtained at 7 months in a girl with Sturge-Weber disease having a right facial angioma, a right pia mater vascular malformation, and seizures since the age of 3 months. Scale represents the CBF values expressed in $\mathrm{ml} / \mathrm{min} / 100$ $g$, the highest in black, the lowest in white; $C B F$ is decreased in the posterior and central right hemisphere whereas it is normal in the left according to age.

\section{Results}

FIRST SPECT EXAMINATION

Although the hemispheric and regional indices were significantly lower in patients with Sturge-Weber disease than in controls $(-0.117$ $v 0.004, \mathrm{P}=0.0137$ and -0.148 v 0.006 , $\mathrm{P}=0.0167$ respectively), no difference was found for absolute CBF values between patients and controls; the population was heterogeneous as both epileptic and nonepileptic patients were included. If we only considered the patients who had had seizures before SPECT imaging (patients 13 to 22), the pattern was more homogeneous as they all had negative indices. They were all significantly lower than in controls (hemispheric -0.262 $v$ $0.01, \mathrm{P}=0.0002$ and regional $-0.340 v 0.019$, $\mathrm{P}=0.0001)$. Absolute $\mathrm{CBF}$ also exhibited lower values in the pathological hemisphere (48.6 $v$ $60.2, \mathrm{P}=0.004)$ and the vascular malformation (44.5 v 62.1, $\mathrm{P}=0.0002)$ than in the other side, thus indicating a constant hypoperfusion of the lesion. Figure 1 shows an example of this pattern. By contrast, indices and absolute CBF values were not different between controls and patients who had never had any seizure before SPECT. Moreover, nine patients $(1,2,3,4,5$, $7,8,10$, and 11) exhibited positive indices whereas only three $(6,9$, and 12$)$ had negative indices, as in the previous epileptic group. When comparing these nine patients with controls, we found significantly higher indices (hemispheric $0.081 v 0, \mathrm{P}=0.0071$ and regional $0.121 v-0.004, \mathrm{P}=0.0027$ ) thus suggesting that the perfusion was higher in the vascular malformation than in the contralateral hemisphere. Figure 2 shows an example of this pattern.

SECOND SPECT EXAMINATION (TABLE 3)

Seven out of these nine patients had two SPECT examinations at a mean seven month interval and three of them $(5,10$, and 11) began seizures between the two studies. At the 


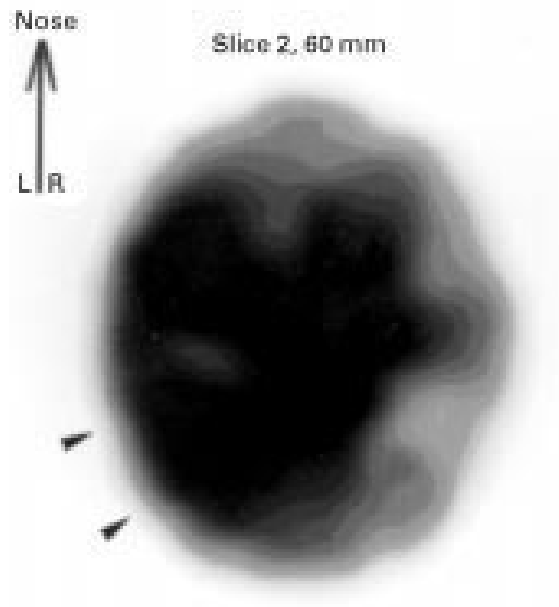

$80-$

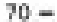

$50-$

$40=$

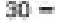

$20-$

Figure 2 SPECT image obtained at 17 days in a girl having a left facial angioma and a left piamater vascular malformation, but no seizures. Scale represents the CBF values expressed in $\mathrm{ml} / \mathrm{min} / 100 \mathrm{~g}$, the highest in black, the lowest in white; $C B F$ is increased in the posterior left hemisphere whereas it is normal in the right according to age.

first SPECT, the indices were significantly increased compared with controls (hemispheric $0.091 v 0, \mathrm{P}=0.0123$ and regional $0.126 v 0, \mathrm{P}=0.01)$ but they were decreased at the second SPECT (hemispheric -0.126v $0.026, \mathrm{P}=0.0144$ and regional $-0.2 v 0.014$, $\mathrm{P}=0.0185)$. The same applied to the subgroup of four patients (1,2,3, and 7) who never experienced seizures but who exhibited hypoperfusion in the vascular malformation at the second SPECT examination (hemispheric index $-0.098 v 0.032, \mathrm{P}=0.0384$ and regional index $-0.135 v 0.013, \mathrm{P}=0.0591)$.

\section{Discussion}

This study provides the first assessment of functional imaging in a series of infants with Sturge-Weber disease at early stages, before the appearance of any seizures. The pattern of perfusion was different from that which has been described in epileptic patients as CBF was increased on the side of the vascular malformation in most patients who had not had seizures.
Then, $\mathrm{CBF}$ tended to decrease at the end of the first year of life, thus confirming that the course of the disease may be spontaneously progressive. Moreover, the classic hypoperfusion of the vascular malformation can be present as early as 2 months of age in the patients who presented with early seizures. This confirms that seizures are responsible for the decreased flow and suggests that epilepsy acts as an additional worsening factor in Sturge-Weber disease.

METHODOLOGICAL CONSIDERATIONS

The SPECT method used for measuring $\mathrm{rCBF}$ by inhalation of xenon-133 has been validated in adults. ${ }^{20}$ The method has been adapted for young and uncooperative children by replacing inhalation with intravenous injection and by adding premedication. ${ }^{19}{ }^{21}$ Because patients and controls have been investigated here with the same procedure, their $\mathrm{CBF}$ values are comparable. Most patients were receiving antiepileptic treatment when SPECT was performed. Antiepileptic drugs are known to induce global functional changes in the brain. Phenobarbitone and carbamazepine decrease brain glucose metabolism and therefore CBF by about $20 \%$ but they do not induce any regional changes. ${ }^{22} \mathrm{~A}$ hypoperfusion restricted to the side of the vascular malformation is therefore unlikely to result from a drug effect. Moreover, such an effect should be cancelled by using a left to right index. Two previous studies reported changes in metabolism and $\mathrm{CBF}$ with age in normal children but they both considered the mean of right and left hemispheric values. ${ }^{19}{ }^{23}$ It seems that asymmetry between the hemispheres exists, even in the first years of life. ${ }^{24}$ In the present study, we therefore chose the control values for each patient according to age and to hemispheric side. Such a procedure allowed us to avoid any artefactual difference due to age or physiological asymmetry.

ETHICAL CONSIDERATIONS

In adults, control populations for PET and SPECT studies are rather easily obtained among normal volunteers. Such a practice is ethically and legally prohibited in children so that a normal control population is unobtainable at this age range. The only means of obtaining control values is to collect a population of children exhibiting transient neurological or apparently neurological events in whom cerebral imaging was needed but who

Table 3 Individual CBF data at second SPECT

\begin{tabular}{lllllllll}
\hline $\begin{array}{l}\text { Patient } \\
\text { No }\end{array}$ & $\begin{array}{l}\text { Age at } \\
\text { SPECT }\end{array}$ & $\begin{array}{l}\text { Seizures } \\
\text { before } \\
\text { SPECT }\end{array}$ & $\begin{array}{l}\text { Hem CBF } \\
\text { angioma } \\
\text { side }\end{array}$ & $\begin{array}{l}\text { Hem CBF } \\
\text { normal side }\end{array}$ & $\begin{array}{l}r C B F \\
\text { angioma } \\
\text { side }\end{array}$ & $\begin{array}{l}r C B F \\
\text { normal side }\end{array}$ & Hem index & Reg index \\
\hline 1 & $10 \mathrm{~m}$ & No & $82(65)$ & $88(62)$ & $89(67)$ & $95(64)$ & $-0.06(0.05)$ & $-0.07(0.05)$ \\
2 & $10 \mathrm{~m}$ & No & $60(64)$ & $80(61)$ & $55(65)$ & $85(60)$ & $-0.29(0.05)$ & $-0.43(0.02)$ \\
3 & $11 \mathrm{~m}$ & No & $69(65)$ & $72(62)$ & $68(60)$ & $71(61)$ & $-0.05(0.05)$ & $-0.04(-0.02)$ \\
5 & $10 \mathrm{~m}$ & Yes & $51(64)$ & $67(61)$ & $39(62)$ & $67(60)$ & $-0.26(0.05)$ & $-0.53(0.03)$ \\
7 & $6 \mathrm{~m}$ & No & $59(54)$ & $59(55)$ & $60(59)$ & $60(59)$ & $0.01(-0.02)$ & 0 \\
10 & $7 \mathrm{~m}$ & Yes & $73(53)$ & $72(56)$ & $59(54)$ & $65(55)$ & $0.01(-0.06)$ & $-0.1(-0.02)$ \\
11 & $7.5 \mathrm{~m}$ & Yes & $63(56)$ & $81(53)$ & $57(49)$ & $72(47)$ & $-0.24(0.06)$ & $-0.23(0.04)$ \\
\hline
\end{tabular}

The values in parentheses correspond to the normal values for the same age. $\mathrm{CBF}=$ cerebral blood flow; Hem $\mathrm{CBF}=$ hemispheric cerebral blood flow; $\mathrm{rCBF}=$ regional cerebral blood flow; Hem = hemispheric; $\mathrm{Reg}=$ regional $; \mathrm{m}=$ months 
were subsequently shown to have developed normally. Two such challenging studies were performed and provided the unique "historical" reference values for metabolism and CBF using FDG-PET and xenon-133 SPECT respectively. ${ }^{19} 23$

FUNCTIONAL IMAGING AT EARLY STAGES OF STURGE-WEBER DISEASE

Up to the present study, the patients with Sturge-Weber disease who had undergone PET or SPECT cerebral imaging, were mostly aged over one year and were all epileptic before imaging. The damaged hemisphere was hypometabolised or hypoperfused. ${ }^{14}{ }^{17}$ The present study shows that such a hypoperfused pattern may already be present before one year when patients have exhibited seizures since the first months of life. As in older children, hypoperfusion extends beyond the abnormalities depicted on CT and MRI as it often affects the whole hemisphere. The remaining population of this study, although affected by SturgeWeber disease, had not yet exhibited any seizures when functional imaging was performed. Before one year of age, SPECT disclosed a paradoxical pattern of increased rCBF in the cerebral cortex of the anatomically affected hemisphere in three quarters of the patients. Such a functional pattern on the side of the vascular malformation is pronounced enough to be detectable not only in the part of the cortex affected by the lesion but also in the whole hemisphere. This paradoxical interictal hyperperfusion has been exclusively seen before the age of one year in our series as well as in other reported cases. ${ }^{14}{ }^{18}$ From our data, interpretating this early pattern remains difficult because of the high interindividual variability of the absolute $\mathrm{rCBF}$ values in young infants. In some patients, $\mathrm{rCBF}$ is increased not only on the pathological side but also on the contralateral side. As a result, the index comparing both sides seems a better means to assess asymmetry between cerebral hemispheres. How can hyperperfusion in infants who never had seizures be explained? The paradoxical pattern of hypermetabolism in isolated infants with Sturge-Weber disease ${ }^{14}$ has been related to a possibly accelerated myelination during the first months of life, as suggested by a few MRI images which disclosed focal hypermyelination in infants with Sturge-Weber disease. ${ }^{25}{ }^{26}$ Although controversial, this hypothesis could also apply to hyperperfusion. Subsequent SPECT imaging in these non-epileptic infants disclosed the typical hypoperfusion seen in older patients with Sturge-Weber disease with seizures. Chugani et al reported a similar shift from hypermetabolism to hypometabolism in an epileptic infant with Sturge-Weber disease who had had two PET studies at eight and 24 months. ${ }^{14}$ Two factors may be causally related to decreased $\mathrm{CBF}$ in our series; the presence of seizures and also the age, as the patients with seizures were older than those without. Therefore, the serial CBF changes we found in the present study suggest that Sturge-Weber disease is a spontaneously progressive disease in which seizures may be an additional worsening phenomenon. Cerebral perfusion is modified in Sturge-Weber disease. ${ }^{27}$ The superficial meningeal vascular malformation is responsible for the obstruction of normal venous return. Then, ischaemia progressively develops in the area of the brain that underlies the vascular malformation and involves cortical and subcortical regions. Obstruction of the normal venous return produces an abnormal drainage into the deep plexus and hypertrophy of the choroid plexus visible on CT. This complex circulatory condition may explain why seizures are potentially severe and usually followed by a defect of blood flow in the area of the vascular malformation. However, the role of seizures in Sturge-Weber disease will only be clarified by ictal CBF studies.

\section{Conclusion}

A study of CBF using SPECT in young infants with Sturge-Weber disease discloses a special functional pattern before the onset of seizures. During the first months of life, the vascular malformation tends to be hyperperfused. The pattern switches to hypoperfusion at the end of the first year, accelerated by seizures and due to progressive ischaemia in the parenchyma underlying the vascular malformation. Further studies are needed to elucidate the role of seizures and to confirm the progressive course in children with Sturge-Weber disease without epilepsy.

1 Alexander GL, Norman RM. The Sturge-Weber syndrome. Bristol: Wright, 1960.

2 Enjolras O, Chiron C, Diebler C, Merland JJ. Nouvelles orientations pour un diagnostic précoce du syndrome de Sturge-Weber. Revue Européenne de Dermatologie et MST 1991;3:21-6.

3 Enjolras O, Riche MC, Merland J. Facial port-wine stains and Sturge-Weber syndrome. Pediatrics $1985 ; 76: 48-51$.

Diebler C, Dulac O. Pediatric Neurology and Neuroradiology. Berlin: Springer Verlag, 1987:99-101.

5 Arzimanoglou A, Aicardi J. The epilepsy of Sturge-Weber syndrome: clinical features and treatment in 23 patients. syndrome: clinical features and treatment

6 Kuhl DE, Bevilacqua JE, Mishkin MM, Sanders TP. The Kuhl DE, Bevilacqua JE, Mishkin MM, Sanders TP. The
brain scan in Sturge-Weber syndrome. Radiology 1972;103: $621-6$.

7 Welch K, Naheedy MH, Abroms IF, Strand RD. Computed tomography of Sturge-Weber syndrome in infants. $\mathcal{F}$ Comput Assist Tomogr 1980;4:33-6.

8 Marti-Bonmati L, Menor F, Poyatos C, Cortina H. Diagnosis of Sturge-Weber syndrome: comparison of the efficacy of CT and MR imaging in 14 cases. AfR Am $\mathcal{F}$ Roentgenol 1992;158:867-71

9 Griffiths P, Blaser S, Boodram M, Armstrong D, HrawoodNash D. Choroid plexus size in young children with Sturge-Weber syndrome. AfNR Am $\mathcal{F}$ Neuroradiol 1996;17: 175-80.

10 Elster AD, Chen MY. MR imaging of Sturge-Weber syndrome: role of gadopentetate dimeglumine and gradient-echo techniques. AfNR Am $\mathcal{f}$ Neuroradiol 1990; 11:685-9.

11 Lipski S, Brunelle F, Aicardi J, Hirsch JF, Lallemand D. Gd-DOTA-enhanced MR imaging in two cases of SturgeWeber syndrome. AfNR Am 7 Neuroradiol 1990;11:690-2.

12 Benedikt RA, Brown DC, Walker R, Ghaed VN, Mitchell $M$, Geyer CA. Sturge-Weber syndrome: cranial MR imaging with Gd-DTPA. AfNR Am F Neuroradiol 1993;14:40915.

13 Marti-Bonmati L, Menor F, Mulas F. The Sturge-Weber syndrome: correlation between the clinical status and radiological CT and MRI findings. Childs Nerv Syst 1993; 9:107-9.

14 Chugani HT, Mazziotta JC, Phelps ME. Sturge-Weber syndrome: a study of cerebral glucose utilization with positron emission tomography. 7 Pediatr $1989 ; 114: 244-53$.

15 Chiron C, Raynaud C, Tzourio N, et al. Regional cerebral blood flow by SPECT imaging in Sturge-Weber disease: an aid for diagnosis. I Neurol Neurosurg Psychiatry 1989;52: 1402-9.

16 Pascual Castroviejo I, Pascual Pascual SI, Viano J, Martinez V, Coya J. Sturge-Weber syndrome without facial nevus. Neuropediatrics 1995;26:220-2. 
17 Bar Sever Z, Conolly LP, Barnes PD, Treves ST. Technetium-99m-HMPAO SPECT in Sturge-Weber synTechnetium-99m-HMPAO SPEC
drome. F Nucl Med 1996;37:81-3.

18 Pedailles S, Martin N, Launay V, et al. Sturge-WeberKrabbe syndrome. A severe form in a monozygote female Krabbe syndrome. A severe form in a monozygc
twin. Ann Dermatol Venereol 1993;120:379-82.

19 Chiron C, Raynaud C, Mazière B, et al. Changes in regional cerebral blood flow during brain maturation in children and adolescents. F Nucl Med 1992;33:696-703.

20 Lassen NA. Cerebral blood flow tomography with xenon133. Semin Nucl Med 1985;15:347-56.

21 Raynaud C, Mazoyer B, Soucy JP, et al. Regional cerebral blood flow (rCBF) measured by SPECT with 133-Xenon: t Med 1988;14:308

22 Theodore WH, DiChiro G, Margolin R, et al. Barbiturates depress human cerebral glucose metabolism. Neurology 1986;36:60-4.
23 Chugani HT, Mazziotta JC, Phelps ME. Positron emission tomography study of human brain functionnal development. Ann Neurol 1987;22:487-97.

24 Chiron C, Jambaque I, Nabbout R, Lounes R, Dulac O, Syrota A. The right brain hemisphere is dominant in human infants. Brain 1997 (in press).

25 Jacoby CG, Yuh WTC, Afifi AK, et al. Accelerated myelination in early Sturge-Weber syndrome demonmyelination in imaging. F Comput Assist Tomogr 1987;11: 226-31.

26 Adamsbaum C, Pinton F, Rolland Y, Chiron C, Dulac O, Kalifa G. Accelerated myelination in early Sturge-Weber syndrome (SWS). MR - SPECT correlations. Pediatr Radiol 1996;26:759-62.

27 Probst FP. Vascular morphology and angiographic flow patterns in Sturge-Weber angiomatosis: facts, thoughts and suggestions. Neuroradiology 1980;20:73-8. 